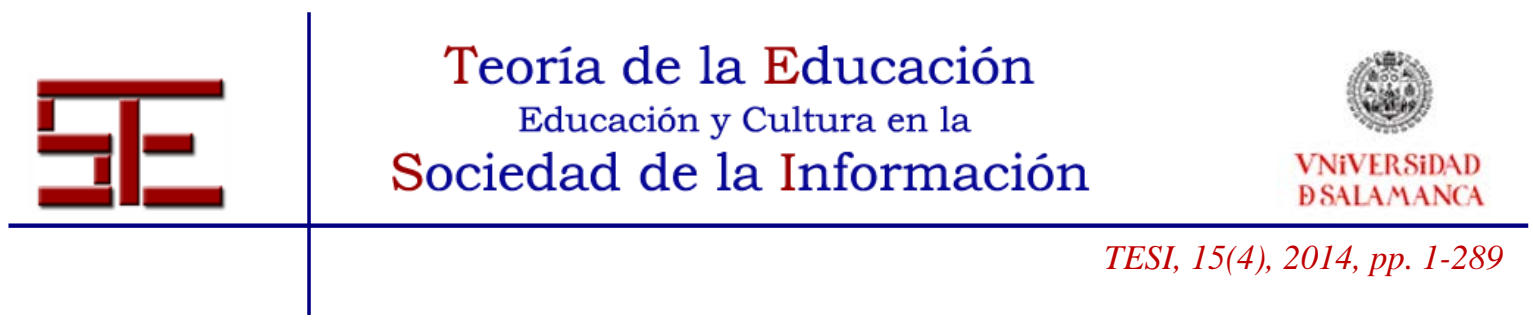

\title{
PERENTORIEDADES DE LOS INVESTIGADORES EMERGENTES: EXHORTACIONES DESDE LA TEORÍA DE LA EDUCACIÓN A MODO DE INTRODUCCIÓN
}

\author{
José Luis GONZÁLEZ GERALDO \\ Universidad de Castilla-La Mancha \\ Joseluis.ggeraldo@uclm.es
}

La auténtica plenitud vital no consiste en la satisfacción, en el logro, en la arribada [...] Un tiempo que ha satisfecho su deseo, su ideal, es que ya no desea nada más, que se le ha secado la

fontana del desear

(Ortega y Gasset, 1930, 72-73)

Encontrar una breve introducción que preceda y sitúe el contenido de los artículos de una revista especializada es algo usual, casi esperado, sobre todo al tratarse de un monográfico. Sin embargo, quizá no sea tan común encontrar monográficos como el que nos ocupa. No tanto por el contenido y estructura de sus artículos como por el hecho de que todos ellos han sido liderados por investigadores emergentes pertenecientes al campo de la Teoría de la Educación. Incipientes neófitos con infinito caudal en su fontana del desear, presente que irrumpe con la esperanza de llegar, en su momento y sin prisas, a formar parte de la memoria del campo de estudio al que ofrecen su esfuerzo y su constancia. De ahí que, al no ser un recopilatorio al uso, como editor crea oportuno elaborar una desacostumbrada y peculiar presentación.

Si en estos párrafos el lector, creo académico, espera encontrar un mero resumen de los textos que conforman este número, siento decepcionarle. Acostumbrados estamos también a localizar esta información al comienzo de cada uno de los artículos y no quisiera ser redundante ni desaprovechar estas líneas redactando únicamente predecibles lisonjas que poco o nada aportarían a las ya de por sí interesantes investigaciones que en breve podrá disfrutar. Los artículos serán presentados, por supuesto, pero con brevedad y a su debido tiempo. Comencemos sondeando previamente el concepto de juventud, así como su relación con la investigación y su futuro.

La juventud, considero, no solo ha de ser divino tesoro a custodiar incluso a sabiendas de su ineludible transitoriedad, sino también estimado momento -impetuoso y fugaz instante- que ha de ser aprovechado para sacar el máximo fruto. Partiendo de esta base y como parte de este elenco de jóvenes académicos, coincido con Rodolfo Llopis cuando afirmó:

Hay que preocuparse de las cosas humanas, y quienes más obligados vienen a intervenir son los jóvenes; la juventud debe desde el primer momento tomar

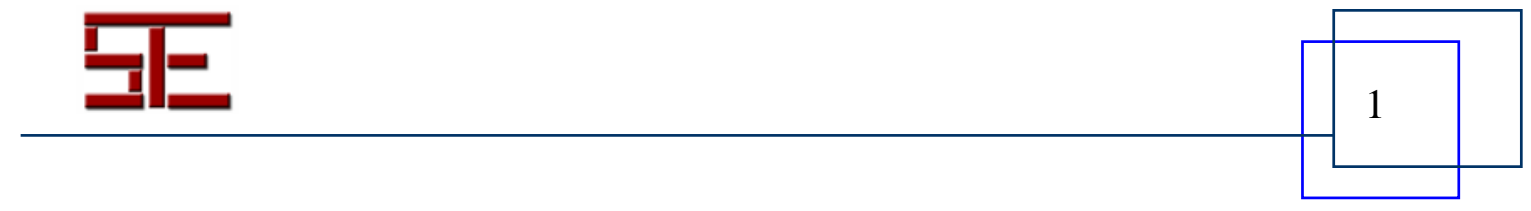




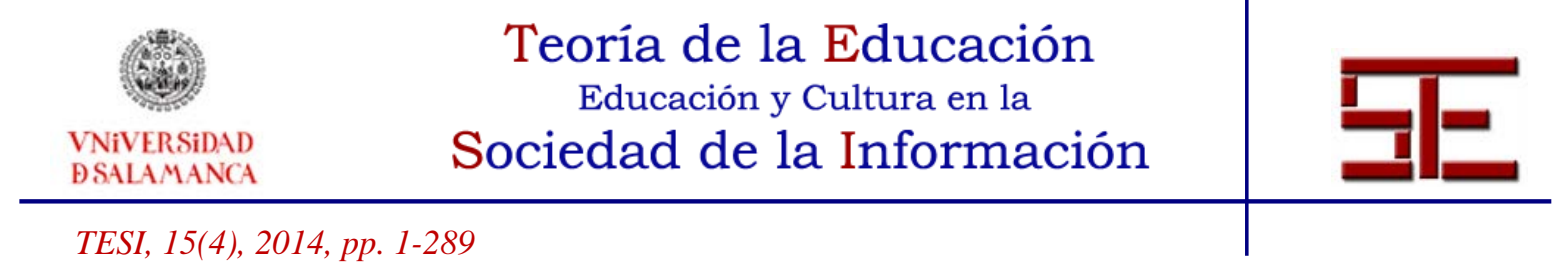

posiciones [...] se rebela contra toda injusticia; que protesta de toda iniquidad; que habla en nombre de las ideas universales. Ser joven quiere decir, para mí, tener ideas generosas en el cerebro, sentimientos elevados en el corazón, normas éticas en la conciencia. (Llopis, 1920, 7-12).

Por este motivo comienzo estas líneas no sólo avisando de la singularidad de esta introducción sino también solicitándole indulgencia a usted, desconocido pero no por ello menos estimado lector. Cómplice indulgencia por la sinceridad de mis confidencias y por el posicionamiento que la ética me ha invitado a tomar en la hora de este preludio, a medio camino entre la vehemencia del marginado Tersites y los idealistas anhelos del intrépido Prometeo.

En una de sus más conocidas obras, La rebelión de las masas, decía Ortega y Gasset que a todo tiempo de plenitud le sigue inexorablemente un periodo de decadencia. Malos tiempos caracterizados por un inasible “todavía no” que terminarán horadando el camino hasta el siguiente cénit historiográfico en el que la humanidad pueda afirmar, ahíta de éxito, otro “por fin”. Atendiendo a la escurridiza altura de nuestros tiempos es inevitable creer que con poco margen de error nos hallamos en una sima desde cuya abismal depresión debemos actuar con el deseo de cimentar un mejor mañana. De ahí que este número de la revista Teoría de la Educación. Educación y Cultura en la Sociedad de la Información, titulado Temáticas emergentes en Teoría de la Educación: nuevas perspectivas y retos de futuro, no pueda entenderse sin escudriñar el porvenir pero acaso también atender a las emergencias que los emergentes investigadores viven y en ocasiones sufren.

Como ya he apuntado, los artículos incluidos en este número están liderados por investigadores emergentes, la mayoría jóvenes académicos en edad y todos jóvenes en espíritu y aspiraciones. Las páginas siguientes son, por tanto, el resultado del generoso ofrecimiento que la revista hizo al querer dar una oportunidad “... a lo que aún no está bien labrado, a lo que, cuando más, es todavía una preparación, un proyecto, una posibilidad, una esperanza" (Ortega y Gasset, 1969, 504). Espero, por tanto, que los más avezados sepan apreciar correctamente el contenido de cada uno de los textos reunidos así como la forma de comunicarlos y las diferencias de calidad que entre ellos, por la simple trayectoria de los autores, sin duda existen. Justificación tan pertinente como innecesaria, pues todos los artículos que finalmente han sido publicados pasaron exitosamente los mismos filtros de calidad, siendo si acaso éste el peor de todos ellos.

Nada más lejos de la realidad, la juventud que rezuma este monográfico no es sinónimo de inexperiencia sino de futuro. Un futuro que emerge desde el presente tomando impulso al tomar el pulso del pasado, si me permiten la iteración. Así, el verdadero desafío de la juventud pasa por respetar la tradición sabiendo que el progreso requiere ir más allá: buscando la vida del futuro en la decorosa muerte del pasado construiremos un decente presente. Si la educación requiere un compromiso con la memoria (Esteve,

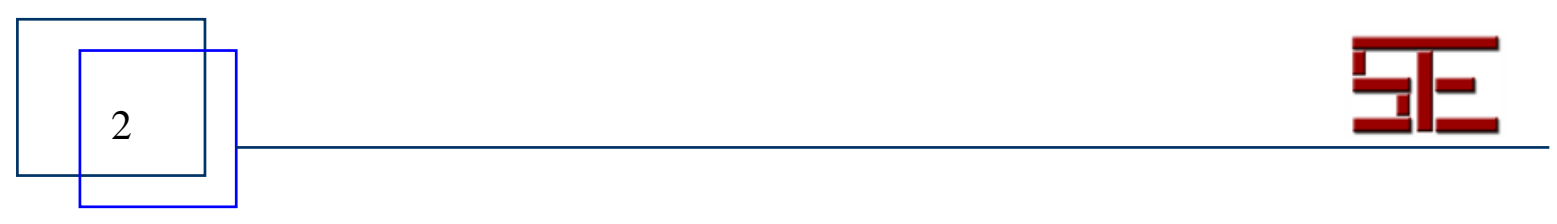




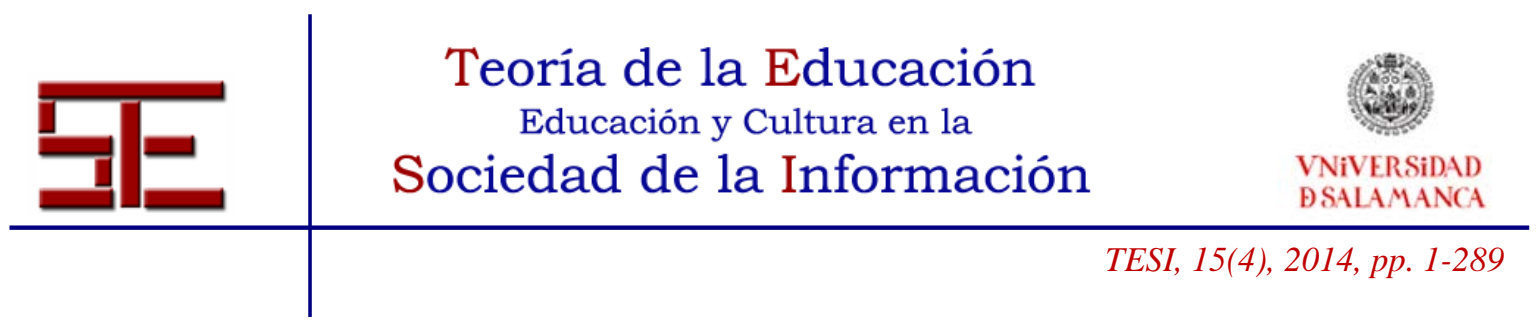

2010), tampoco es menos cierto, en palabras del conocido personaje de Hesse, que "El pájaro rompe el cascarón. El cascarón es el mundo. Quien quiera nacer, tiene que destruir un mundo" $(1975,87)$.

Este razonamiento contrasta fuertemente con la apatía generalizada con la que la juventud en ocasiones suele exigir un futuro digno. Futuro que debe sembrarse con acciones y no sólo a expensas de las ya realizadas por las generaciones que nos precedieron. Curiosamente, fue un joven Ortega quien ante la mítica sociedad El Sitio nos recordó, al exponer su percepción sobre la patria, cuál pudiera ser la postura que la juventud habría de tener (Ortega y Gasset, 1969). Partiendo de las ideas de Nietzsche, Ortega distinguió entre dos patrias: la de nuestros padres y la de nuestros hijos. La primera como condensación del pasado, como alegría del disfrute de lo alcanzado; la segunda como algo que todavía no existe, duro futuro en potencia a conseguir no sin cierto esfuerzo e incluso dolor. Dejando de lado las connotaciones políticas que entraña el concepto de patria, pero sí quedándonos con la aspiración de los deseos que esta idea supone, sus palabras envían un claro mensaje a los más bisoños: "El dolor, señores, es un severo cultivo; la alegría es sólo la cosecha; en el dolor nos hacemos, en el placer nos gastamos” (ibíd., 504). Si la juventud desea un mejor mañana es imprescindible que se esfuerce y haga méritos para conseguirlo. No sólo reclamando y gastando lo ya sembrado por otros conseguiremos un mejor mañana.

No obstante, quien mira exclusivamente al futuro puede quedar deslumbrado por el presente, siendo incapaz de distinguir la bondad o necedad de los futuribles que ante sí se despliegan. Hablar de futuro sin examinar el presente carece de sentido y ahí radica la emergencia de señalar y compartir ciertos matices y realidades que hoy afectan al mundo universitario $\mathrm{y}$, dentro de él, muy especialmente a los jóvenes académicos: muchos de nosotros docentes apasionados por vocación y todos, por distintos motivos, prolíficos investigadores en potencia.

Porque una cosa es aceptar el reto y la responsabilidad de construir con esfuerzo el futuro que deseamos, pero otra totalmente bien distinta es encontrar obstáculos continuamente en el camino. Trabas y obstrucciones casualmente dispuestas de manera estratégica con la intención, pudieran algunos maquiavélicamente pensar, de impedir el correcto avance de la juventud y, con ella, el de la sociedad en su conjunto. Antes de proseguir, conste que hablo de sociedad y no de campo de estudio porque de nada serviría el avance de la Teoría de la Educación si no tuviera reflejo en la comunidad. Por todo, y pese a que quizá no sea el lugar más oportuno, considero que es el momento ideal de señalar algunos de esos obstáculos, piedras, hitos o mojones. No se trata de volver a entonar el tierno y demodé leitmotiv del sesenta y ocho "seamos realistas, pidamos lo imposible", pero siempre es tiempo de defender con firmeza el sitio que, por esfuerzo y trabajo, día a día labramos y sembramos los jóvenes académicos.

La Universidad, como cualquier otra institución humana, y en concreto la afincada en

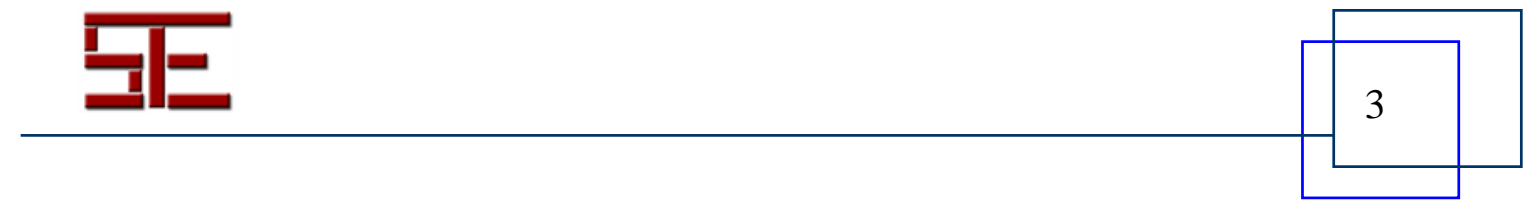




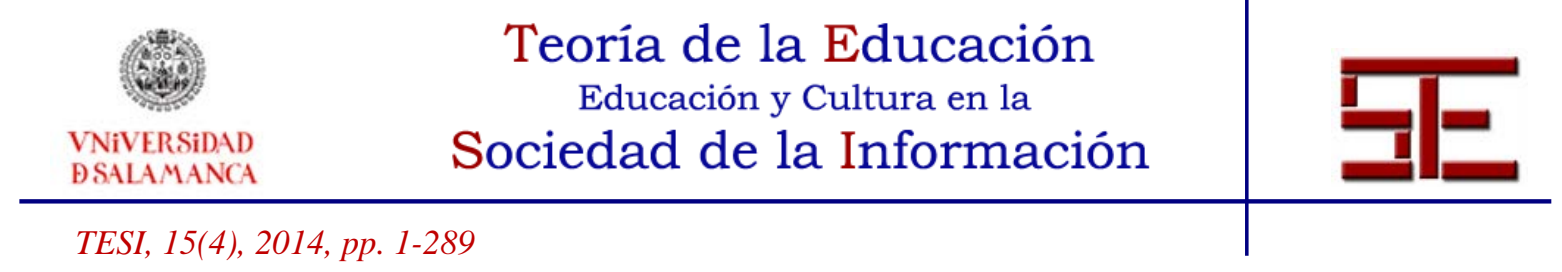

nuestro país, nunca ha estado exenta de críticas que con mayor o menor fundamento han venido complicando el desarrollo de sus funciones y la eficiencia de sus acciones (Orlandis, 1966; Aguilar, 1967), en algunos casos incluso sobrepasando la estricta esfera profesional (Penalva, 2011). Dicho esto, y quizá en parte porque en tiempos de escasez se mira con más detalle lo que se disfruta, todavía hoy existen claras evidencias de que el homo academicus (Bourdieu, 2008), así como su ecosistema, están lejos de la perfección. Un tabú que pocos exorcizan en público y que progresivamente seca la fontana del desear de los que en este mundo nos encontramos, bien sea en Teoría de la Educación o en cualquier otro campo.

Afortunadamente el silencio no siempre prevalece. En septiembre de 2014 el profesor António Nóvoa fue uno de los ponentes principales de la European Conference on Educational Research (ECER) y disertando bajo el título "What is Educational Research For?” todo parecía indicar que los asistentes hallaríamos otro científicoapologético discurso cuando, en verdad, escuchamos uno de los alegatos más realistas y sinceros que quizá se hayan pronunciado recientemente en ambientes académicos. Baste compararlo con las ideas aquí expuestas para entender el gran calado que tuvo en el que suscribe. Sin entrar en detalle, el profesor Nóvoa señaló sin reparos la toxicidad del mundo universitario. Un mundo, y sigo parafraseándole, donde la cultura del "Publish or Perish” distrae a los investigadores hasta el punto de convertirlos en involuntarios pero necesarios cómplices de un perverso sistema donde la mera supervivencia es lo único que parece importar.

De manera preocupante, y en cierta forma, es cierto. Ni podemos ni debemos engañarnos al respecto. Timos y fraudes académicos como el del veterinario Hwang Woo-suk (ABC, 2012) o la científica Haruko Obokata (The Independent, 2014), junto con el todavía más increíble caso del imaginario y productivo Ike Antkare (Labbé, 2010) o el más reciente experimento Pantani-Contador (López, Robinson y Torres, 2012), sin olvidar las críticas del Premio Nobel Randy Schekman (El País, 2013), deberían ser suficientes para hacer saltar todas las alarmas. Sin embargo, lejos de solucionarse y más allá de los lavados de cara que acontecen tras la aparición de noticias de este tipo, el problema se incrementa hasta el punto de encontrar producciones científicas que han sido publicadas gracias a un simple pero ingenioso programa informático que, con sólo darle a un botón, elabora pedantes galimatías capaces de burlar una revisión por pares (The Guardian, 2014; Nature, 2014).

El razonamiento es simple. Los investigadores, especialmente los más vulnerables y la juventud puede entenderse como un lastre desde este prisma, se encuentran bajo una tremenda presión que les impulsa a publicar compulsivamente para poder encontrar estabilidad laboral, reconocimiento y promoción. Por otro lado, algunas revistas especializadas se aprovechan de dicha necesidad para transformar artículos en beneficio, y así el círculo queda sellado para ponerse en marcha y llenar los anaqueles

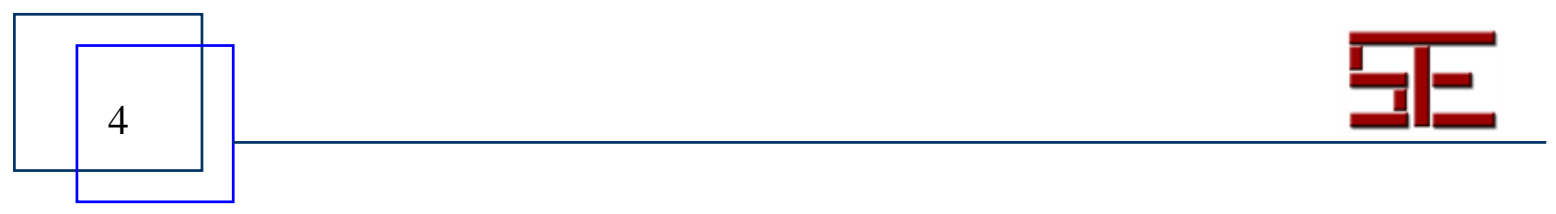




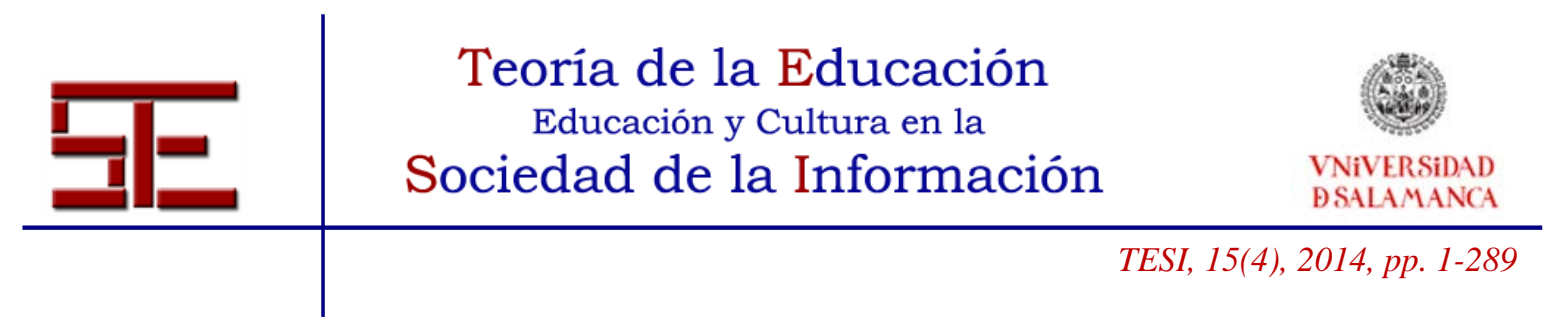

de vicio y ruido. Ruido y no música, como debería ser, pues otra de las más nocivas consecuencias de esta cadena de publicaciones y citas es el innecesario incremento de la producción científica, siendo cada vez más difícil encontrar textos que realmente valgan la pena. Afortunadamente, y aunque la decisión final siempre queda exclusivamente en manos del lector, éste no es el caso.

No todo lo que hace el académico ha de ser publicado. No a menos que su trabajo sea única y exclusivamente el de investigador, que no suele ocurrir. El impacto de sus acciones excede y no se limita al negro sobre blanco. Antes de investigadores somos personas $\mathrm{y}$, entre medias, la gran mayoría también somos docentes que trabajan, nunca debemos olvidarlo, en una institución de educación superior. Su huella pedagógica, por tanto, es más larga que su sombra investigadora. ¿Para qué, pues, está realmente la universidad y sus miembros? Volvería a ser oportuno acudir a Ortega para releer su Misión de la Universidad, pero no sería sensato dispersarnos todavía más introduciendo diatribas basadas en aspectos pedagógicos (ver González Geraldo, 2014a). Esta combinación, no obstante, sería vital a la hora de entender por qué algunos compañeros consideran que el académico universitario -perfil principal de este monográfico- puede reducirse una parodia del cliché del hombre orquesta o vendedor de ultramarinos, tan versátil como atribulado (Ramió, 2014).

Bajo estas reflexiones, declaraciones como el Manifiesto por unas universidades a la altura de sus misiones (UNIVENDEBAT, 2012) o The Slow Science Manifesto (The Slow Science Academy, 2010) nos animan a replantearnos un escenario donde la afanada juventud investigadora pueda encontrar honrada y cabalmente su lugar. Centrándonos en la actividad investigadora de todo académico y recogiendo las ideas de estos dos últimos textos, no puedo sino coincidir con ellos cuando sentencian que, de no cambiar las cosas: "el investigador y el docente apasionados corren el peligro de perder sus ideales” (UNIVENDEBAT, 2012) o que los investigadores, sin que deje de ser una perogrullada, tienen ciertas necesidades indispensables:

We do need time to think. We do need time to digest. We do need time to misunderstand each other, especially when fostering lost dialogue between humanities and natural sciences. We cannot continuously tell you what our science means; what it will be good for; because we simply don't [sic.] know yet. Science needs time. Bear with us, while we think. (The Slow Science Academy, 2010)

Desgraciadamente, escribimos demasiado y cada vez tenemos menos tiempo y deseo de leer lo que otros redactan. Cuando pensar sólo parece ser una opción si dejará constancia en nuestro expediente, es tiempo de cambiar de actitud. Algo que no puede legarse exclusivamente a las entusiastas pero también inexpertas manos -cabezas y corazones- de los más novatos. En este asunto estamos todos implicados. Pese a ser sinónimo de futuro, la juventud no es nada si no se encuentra respaldada por el pasado, la pericia, la veteranía y la maestría del experto.

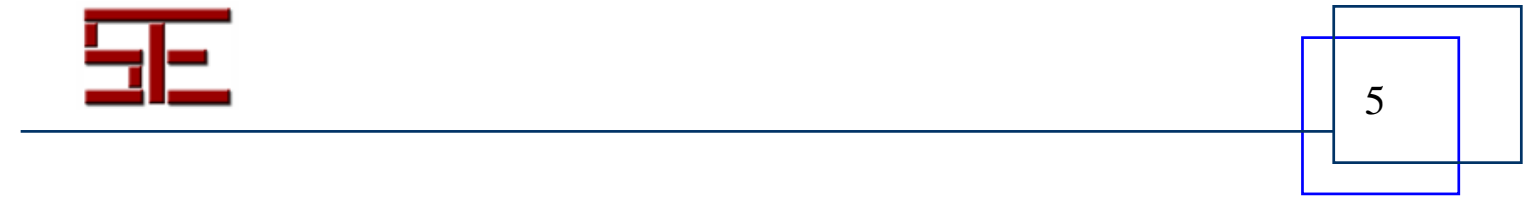




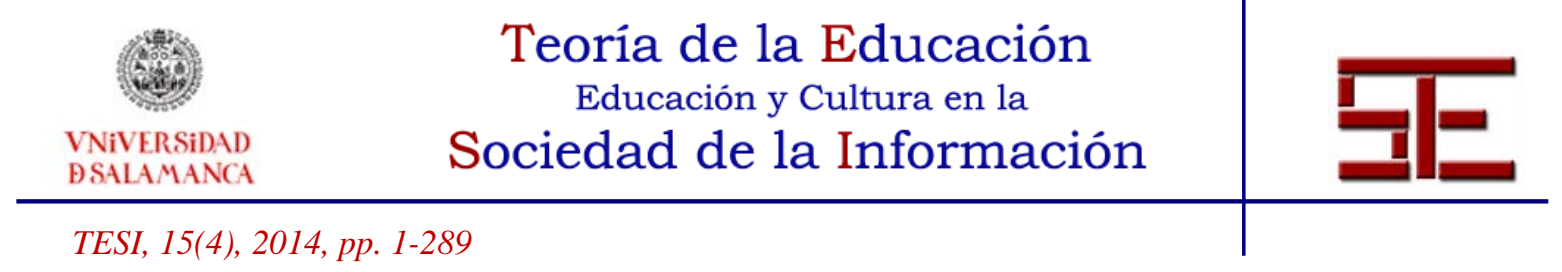

Por estos motivos, al igual que anteriormente renegaba de la desfachatez con la que la juventud en ocasiones pide sin merecer, no puedo dejar pasar la ocasión de recordar la necesidad -incluso la obligación moral- de ayudar a los que abrazando la educación con la misma pasión que desprenden en sus investigaciones, creen en sus ideales sin tener por ello que someterse a las directrices del éxito: siempre variables, volubles y variopintas en función del momento histórico que tomemos. En este sentido, y salvando las evidentes distancias, dejaré que sea Francisco Giner de los Ríos -cuyo centenario celebraremos en breve- quien clarifique este llamamiento:

A esa juventud inteligente, activa, enérgica, que quiere vivir, no vegetar, y a quien no arredra la lucha, se le ofrecen dos caminos harto diferentes. Comienza el uno en la abdicación de todas las ideas generosas que siente hervir en su espíritu y conduce a la gloria y al éxito. El otro, fiel a esas mismas ideas, lleva las más veces a la oscuridad y casi siempre al infortunio. ¡Y ha de elegir entre ambos! [...] Mas culpe del rigor de su suerte, no a la naturaleza humana, cómoda excusa contra toda tentativa de reforma, sino precisamente a la pusilanimidad de sus predecesores. Si éstos no se hubieran apresurado a reverenciar la misma tiranía de que murmuraban, la vida sería hoy harto más grata, la virtud más fácil y menor el sacrificio, a cuya divina fecundidad no hay poder que sobrepuje en la tierra. (Giner de los Ríos, 1922, 121-122).

Antes de proseguir, evitemos cualquier malinterpretación. Con estas últimas palabras no pretendo realizar una indiscriminada crítica haciendo mía la peligrosa máxima destruam et aedificabo. Este monográfico, así como otras iniciativas tales como la cada vez más consolidada Red IPTE, son claras evidencias de la convivencia armónica entre la experiencia de los años y la vehemencia de la juventud. Dicho esto, sí que creo necesario y oportuno remarcar hoy estas ideas para evitar lamentar mañana no haberlo hecho y, de paso, conseguir que las necesidades y urgencias de la juventud lleguen, gracias a la experiencia de los que nos preceden, a las esferas donde se toman las decisiones y se rubrican los documentos. En ocasiones se habla de comisiones, grupos y distintos equipos de trabajo como si en realidad no estuvieran formados por personas, compañeros académicos al fin y al cabo. A ellos apelo y dirijo estas exhortaciones. La cooperación de los investigadores ya consolidados se presenta como un requisito sine qua non para el correcto progreso de la disciplina, pero también de las personas que en ella viven.

Y digo viven con ansías de deseo más que contrastando una realidad, pues los jóvenes investigadores de nuestro país, muchos de ellos profesores universitarios en ciernes, han de superar niveles de exigencia nunca antes vistos, estando cada vez más acostumbrados a sobrevivir en la universidad que a vivir la universidad. Llegados a este punto, me es inevitable recurrir a las palabras de otro gran referente de nuestro campo. Rousseau, en su galardonado y célebre discurso sobre las ciencias y las artes, dejó escrito:

Nuestras almas se han corrompido a medida que nuestras ciencias y nuestras artes han avanzado hacia la perfección. ¿Se dirá que es una desgracia inherente a nuestra época?

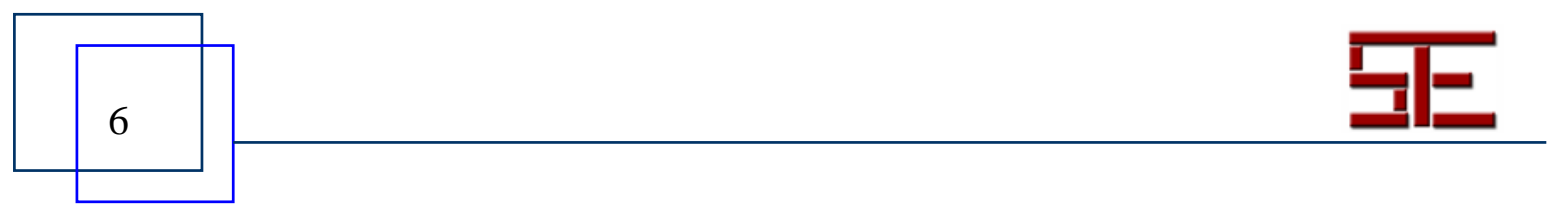




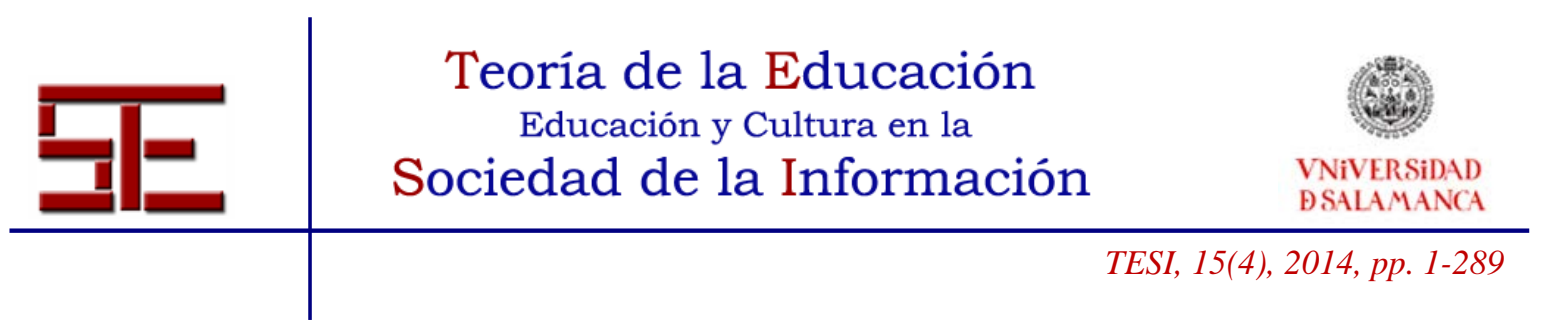

No, señores; los males causados por nuestra vana curiosidad son tan antiguos como el mundo. (1997, 221-222).

Tan antiguos como actuales, en verdad. El excesivo énfasis que sobre otros aspectos quizá se esté prestando a la mera productividad de los investigadores cae como una pesada losa sobre aquellos que comienzan su andadura en la academia, viéndose inmersos en una maquiavélica maquinaria que no dudará en dar con ellos, como en la popular Bildungsroman de Hesse, bajo las ruedas (2005a). Máxime en un momento donde las circunstancias han provocado no sólo la práctica imposibilidad de iniciar carrera académica sino también el estancamiento de los que habiéndola comenzado ven reducidas al mínimo su progreso, creándose un perverso efecto “cuello de botella" cuando no de fuga de cerebros- que probablemente sufriremos durante años. Por todo, las prioridades a las que dirigimos voluntaria o inconscientemente nuestros esfuerzos han de ser expuestas y juzgadas cuanto antes. Hannibal ad portas: la decisión es tan nuestra como nuestras son las responsabilidades derivadas.

Aceptémoslo. Es ciertamente difícil, cuando no imposible, encontrar algún compañero que de una manera u otra no tenga la palabra "impacto" entre sus prioridades más acuciantes. Bien sea por un interés relacionado con aspectos de promoción y consolidación laboral -anteriormente apuntados- bien por la lógica preocupación de quien desea que sus esfuerzos cristalicen en la práctica o, lo que es más común, por una ecléctica mezcla de ambos en función de la situación en la que se encuentre, el investigador actúa por y para conseguir que su obra impacte. Escurridizo concepto, pues al hablar de impacto académico decipimur specie recti (González Geraldo, 2014b). Centrándonos en nuestro ámbito, y con un sano espíritu autocrítico, es áspero encontrar visos de certidumbre ante las palabras de Ruiz Paz:

Si alguien ha participado activamente en sembrar el desconcierto [...] estos han sido los pedagogos. Nos referimos a la pedagogía oficial, desde luego [...] un objetivo, un fin último, una misión: demostrar al mundo que la pedagogía era una ciencia y el pedagogo su profeta. (Ruiz Paz, 1999, 13-14).

Si Rousseau recogió las inquietudes de Egipto y Grecia al reflexionar sobre la creencia de que cierto dios, enemigo de la tranquilidad de los seres humanos, fue el fundador de las ciencias, defendiendo la sugerente idea de que las ciencias y las artes fueron engendradas por nuestros vicios (Rousseau, 1997), quizá es hora de preguntarse públicamente qué vicios y debilidades han sido los que nos han llevado a un punto donde publicar por publicar -o por no perecer-, como si viviéramos en la folletinesca era de Hesse (2005b), provocan en el investigador la sensación de estar meciéndose en la universidad: moviéndose sin llegar realmente a ninguna parte. Todo, claro está, aceptando que estos párrafos se centran exclusivamente en los ámbitos donde investigación y enseñanza universitaria están condenados a entenderse, pues nada se ha dicho ni se dirá aquí sobre la investigación independiente de la educación superior.

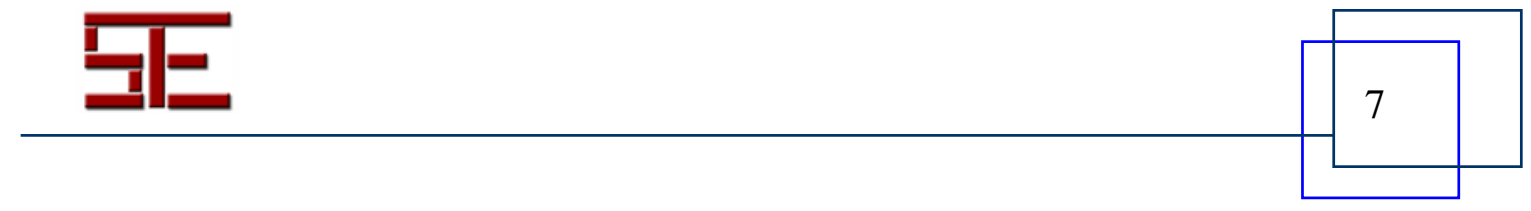




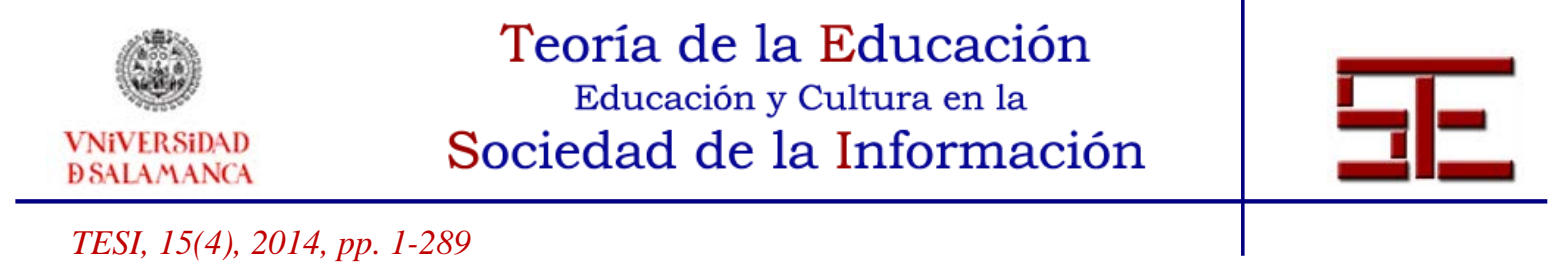

Pero basta de plañideras certezas o debatibles imploraciones. La emergencia ya ha sido expuesta y lo emergente debe ser tratado con corrección. De esta manera, y bajo inspiraciones contraculturales -propias de la juventud (De Villena, 1975)- me gustaría que el lector reflexionara sobre el símbolo Mang del I-Ching, o libro de los cambios. Símbolo significativamente interpretado como "locura juvenil” o "inmadurez" y que nos ha de servir de nexo para entender la relación entre la emergente juventud y la afianzada experiencia. He aquí su descripción:

Yo no voy a buscar al joven inexperto, sino que él viene y me busca a mí. Cuando él demuestra la sinceridad que caracteriza a la primera aproximación al conocimiento, yo le instruyo. Si me pide una segunda y tercera vez, eso es molesto, y yo no instruyo a los que son molestos. Será conveniente mantenerse firme y correcto, como montaña sobre el agua (I-Ching citado en Martínez, 1976, p. 37).

Montaña sobre agua. Así queda representado gráficamente este símbolo. Claridad que nos sugiere la relación que bien pudiera existir entre los consolidados académicos y los jóvenes investigadores. Los primeros como imprescindibles referentes que sirven de patrón, mapa y brújula. Los segundos como fuente que emerge sin tener clara la dirección a tomar hasta que por voluntad propia demuestran con hechos y paciencia el deseo de dejarse guiar a través de indicaciones que permitan al joven comportarse como agua que fluye, con mayor o menor fuerza.

En función de estas premisas es lícito entender como jóvenes investigadores a aquellos que han sabido encontrar su sitio dentro de las corrientes ya establecidas, pero también a los que a base de erosionar progresivamente el cauce, o por la crecida puntual de su caudal, sobrepasan las expectativas. Quizá desde esta perspectiva podríamos seguir jugando con las palabras al diferenciar investigaciones que emergen, surgen o fluyen, de otras que brotan, irrumpen y casi hierven. La mayoría de las investigaciones recogidas en este monográfico presentan más aspectos coincidentes con el primero de los supuestos que con el segundo. Algo lógico, pues de lo contrario sería ciertamente difícil establecer verdades intersubjetivamente compartidas y el progreso de nuestro campo, como ciencia que es, estaría a merced del caos o del influjo de la genialidad, apoyando de manera colateral a aquellos que abogan por una digna apoptosis de la Teoría de la Educación (Carr, 2006).

Paralelamente también sería oportuno reflexionar sobre si es cierto que, salvo contados casos en que se destruyen y crean paradigmas como si de mundos se tratara, el avance científico se basa en progresivas acumulaciones de resultados, reavivando con ello el viejo debate sobre la invisibilidad de las revoluciones científicas y la linealidad o brusquedad de su devenir histórico (Kuhn, 2001, 212). Pero siendo consciente del breve papel que ineludiblemente he de cumplir en esta introducción, ya es momento de ir cerrando estos pensamientos para así presentar, como quizá debiera haber hecho desde el principio si no me hubiera dejado guiar por mi joven corazón, a los verdaderos

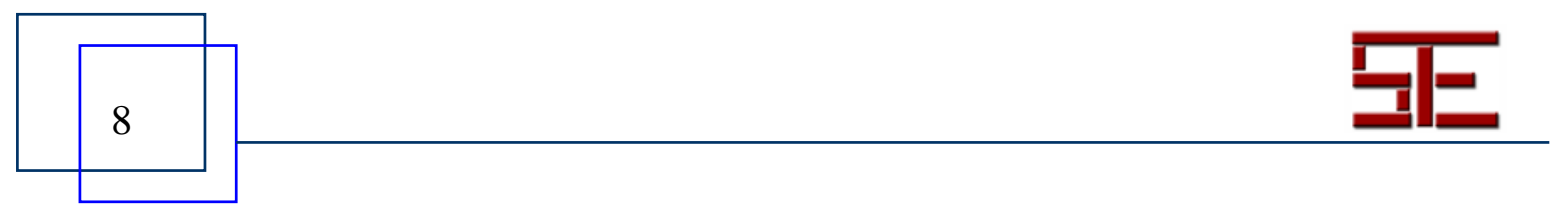




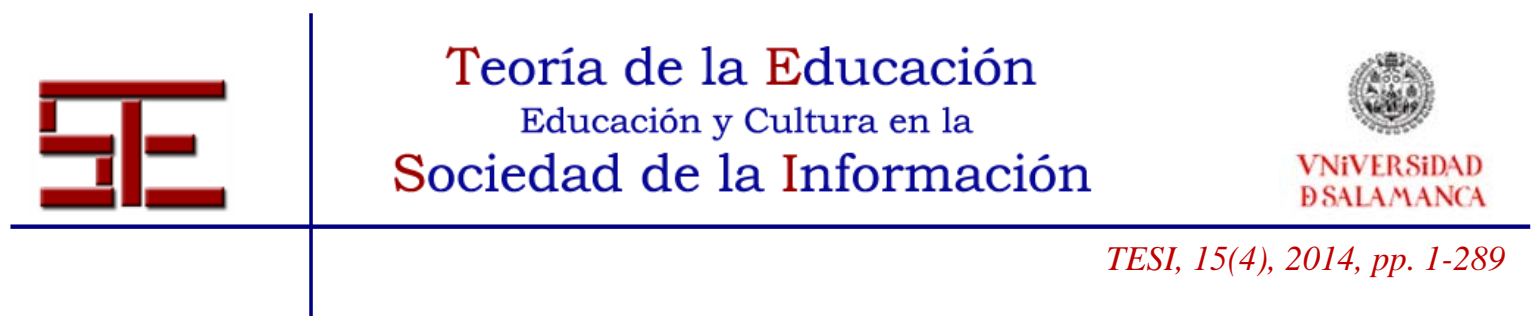

protagonistas del este número.

Abre el monográfico el artículo titulado "La Pedagogía Líquida: ¿Imaginario Pedagógico o Teoría de la Educación?”. En él, y bajo el amparo de la terminología por la que Zygmunt Bauman se ha hecho mundialmente conocido, Xavier Laudo nos invita a seguir reflexionando sobre cómo las propiedades y estados del agua, líquido por antonomasia, pueden sernos de gran utilidad a la hora de comprender el presente y el futuro del campo educativo y de la teoría que, con mayor o menor certeza, lo sustenta. La incertidumbre y flexibilidad propia del postmodernismo que rezuman sus párrafos queda patente desde el principio en el espíritu que le impulsa a compartir sus razonamientos, algo que denota al mismo tiempo no sólo su compromiso investigador sino también la dedicación que como docente adquiere al trabajar en el ámbito universitario: "No tengo respuesta cerrada a ninguna de esta preguntas y es por ello que presento este texto a la comunidad científica con el único ánimo de compartir las preguntas y seguir pensando junto con mis colegas del área y mis estudiantes” (Laudo, 2014, 19).

El testigo es recogido por Ana Jofre y Stephanie M. Mari, quienes usando la lengua de Shakespeare nos exponen un sugestivo estudio de caso con la pedagogía constructivista como arma principal y la enseñanza de la ciencia como campo de batalla. Sin limitar el espectro de la primera a las meras disposiciones filosóficas y siendo conscientes del carácter realista de la segunda, las autoras aportan evidencias que respaldan el plausible uso de esta pedagogía con los correspondientes beneficios colaterales que van más allá del correcto aprendizaje de los hechos científicos pretendidos. Tal y como ellas mismas afirman: "Allowing students to construct their own path toward knowledge helps them better "make sense" of the knowledge in their own words and in relation to their own experiences” (Jofre y Mari, 2014, 34). Quizá el resultado objetivable es ciertamente el mismo que el que puede ser alcanzado con otras metodologías, pero el sendero de aprendizaje recorrido -en ocasiones más de uno gracias a los errores- nos recuerda que a la hora de educar quizá no se trate tanto de la posada, del resultado, sino del camino, del método etimológicamente interpretado.

Del camino pasamos al verbo que lo sustenta gracias a la pluma de Jordi García Farrero, de quien recibimos una peripatética invitación para interpretar la pedagogía desde una interdisciplinar visión del acto de caminar. Con su atractiva narración, Jordi nos retrotraerá a aquellos atribulados paseos rousseaunianos, a la literatura de viajes de Goethe y a las solitarias y fecundas caminatas de Nietzsche. Inevitablemente, reflexionar sobre el Homo viātor en el presente monográfico ha de servirnos como una posible metáfora de juventud: caminar como debate entre lo que está delante y lo que está detrás, o quizá como eterno proceso hacia la inasible pero deseada perfección, pues bien sabe el equilibrista que en la quietud reside la fatalidad. Razonamientos que nos instan, literalmente, a dar un paso al frente:

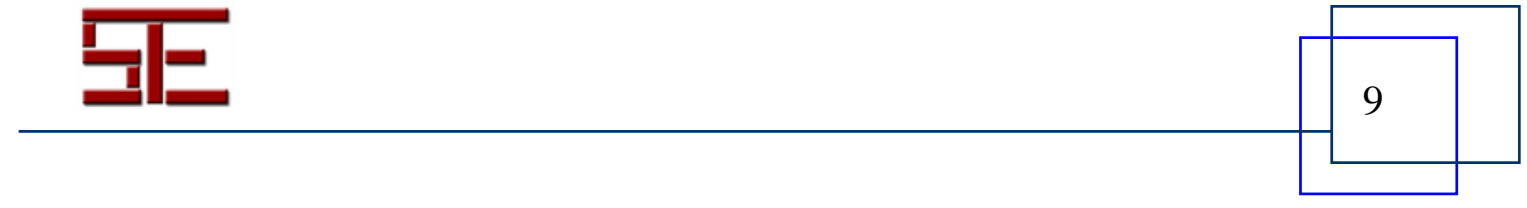




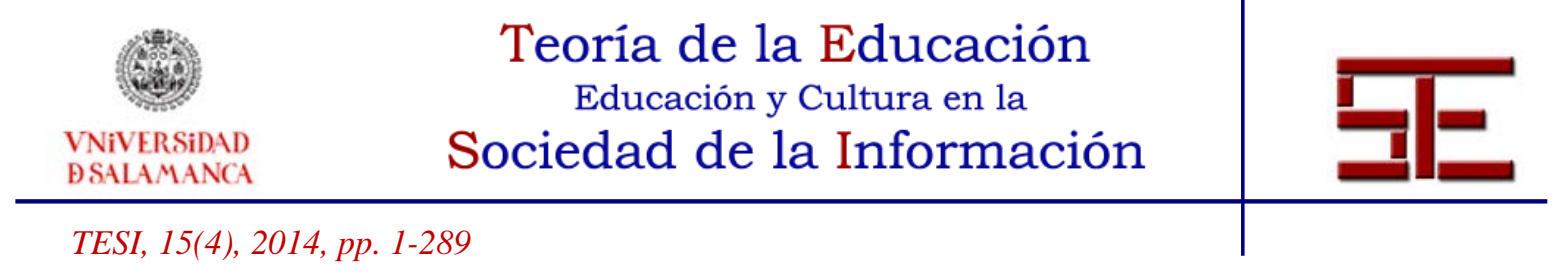

... es una invitación a ponernos en marcha, a llenar de sentido los trayectos y a disfrutar de una vida a la intemperie [...] porque nos humaniza proporcionándonos tiempo y, además, vuelve más habitable este mundo ante unos valores que cada vez priorizan más lo que transmite el espíritu automovilístico y tecnológico (inmediatez, velocidad, superficialidad o ligereza). (García Farrero, 2014, 56).

En cuarto lugar el lector hallará el texto de la profesora Arbués titulado "Presente y futuro en el ámbito de la educación para la ciudadanía en Europa”. En él encontramos un necesario y apasionado alegato en favor de una eficiente educación cívica en la que, entre otros aspectos, puede destacarse el relevante papel que la universidad ha de desempeñar al albergar en sus aulas a los que en el futuro serán los protagonistas de todo cambio que se avecine: "Y es que también desde la universidad se puede contribuir a elevar el grado de cultura cívica, incidiendo en aspectos relativos a la convivencia y a la cohesión social” (Arbués, 2014, 85). El análisis realizado, junto con las recomendaciones sugeridas para alcanzar un mejor mañana, hace que su lectura sea obligatoria en estos tiempos de cambio.

Por su parte, el compañero Pablo Sánchez Antolín, en colaboración con el profesor Paredes Labra, efectúa una exhaustiva revisión de las políticas educativas que han llevado a la integración de las Tecnologías de la Información y la Comunicación (TIC) bajo tres niveles: Unión Europea, España y la región de Madrid. Huelga comentar el importante papel que las TIC juegan como catalizadores de las aspiraciones educativas, quizá demasiado centradas en su devenir sobre el aspecto exclusivamente escolar y con algunos retos -como la correcta formación del profesorado- todavía por resolver tal y como señalan los autores en el propio cuerpo del artículo (Sánchez y Paredes, 2014, 107).

Una temática muy afín a la redactada, en este caso en portugués, por Natália Fernandes y María José Hernández en el artículo “Tecnologías y modelos de aprendizaje emergentes en educación superior. Propuestas y difusión de innovaciones”. Nada extraño cuando el aprendizaje y las ya nada nuevas -pero siempre punteras- TIC deben compartir destino de manera irremediable. Con su trabajo, las investigadoras exploran la huella que los diferentes modelos analizados presentan en el ámbito universitario: Flipped Learning, Personal Learning Environments, Mobile Learning y los cada vez más mediáticos Massive Open Online Course (MOOC). Estrategias atractivas pero no por ello fáciles de implementar, pues una de las principales conclusiones apuntadas por el estudio es que su utilización no suele ser tan rápida y clara como en un principio nos gustaría: "Sendo que grande parte das vezes a sua introdução e adapatação é um processo demorado e complexo" (Fernandes y Hernández, 2014, 134). Salvando las distancias de los dos últimos artículos, es inevitable cuestionarse cómo una correcta formación del profesorado pudiera facilitar la adaptación de estas metodologías.

Sin salirnos completamente del ámbito explorado en las dos últimas investigaciones,

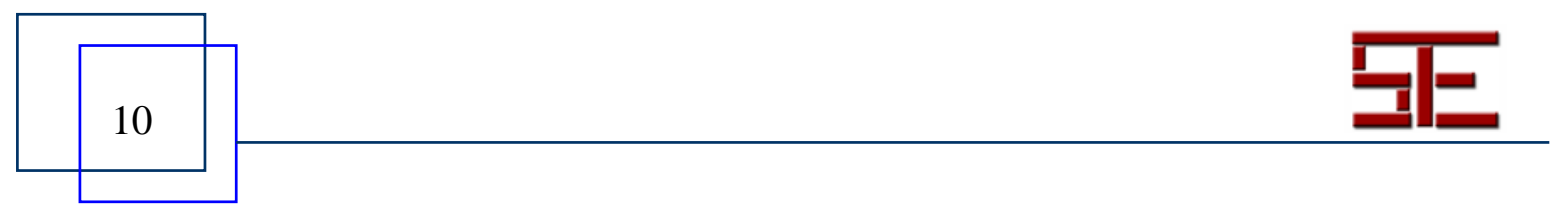




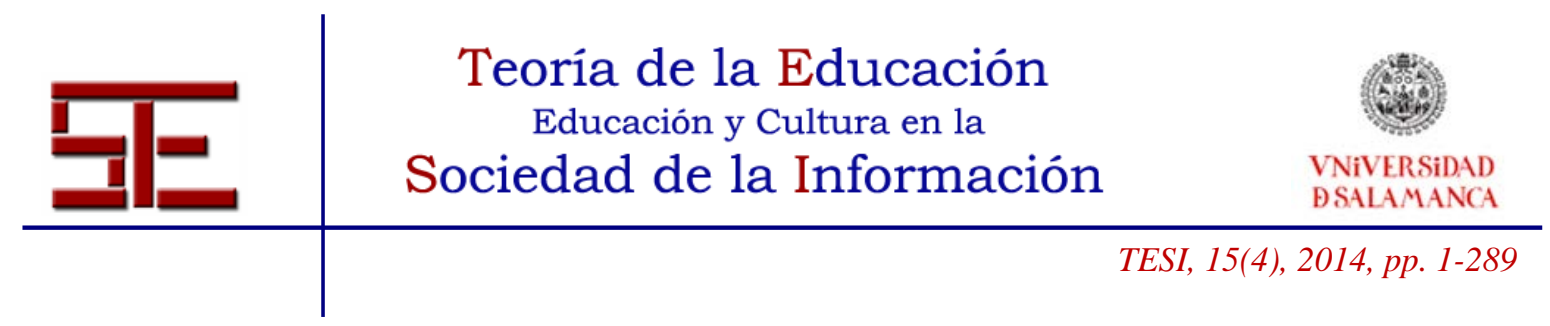

pero en este caso concretándolo en el uso de los videojuegos, hallamos el texto de las compañeras Laura Alonso y Rocío Yuste "Teorías de la educación de adultos que subyacen en el uso de videojuegos”, una interesante y original combinación. Tras haber profundizado en la relación que existe entre videojuegos y adultos las autoras se han encontrado con un gran vacío en cuanto a literatura existente al respecto. Evidencia que denota la emergencia de la investigación que han llevado a cabo pues como ellas mismas indican: “... somos conscientes de que se trata de un área emergente, en la que aún queda mucho por hacer” (Alonso y Yuste, 2014, 161). Pese a que es un lugar común aceptar el uso de estos juegos por parte de la infancia, adolescencia y juventud, poco se ha explorado en relación con la población adulta y la tercera edad, motivo por el que las investigadoras Alonso y Yuste, como punto de partida de un camino lleno de oportunidades, elaboraron un cuestionario cuyas particularidades podrá el lector en breve apreciar.

A continuación encontramos el artículo “'Las palabras son también hechos: Quentin Skinner, el giro contextual y la Teoría de la Educación” donde sus autores, Jon Igelmo y Patricia Quiroga, comparten las posibilidades hermenéuticas que el giro contextual presenta para nuestro campo al clarificarlo con las teorías de Ivan Illich y Rudolf Steiner. Un retorno al contexto inicial de las ideas donde las palabras ya no son interpretadas aisladamente, pues las circunstancias y las acciones de quienes las originaron también han de ser consideradas. Con esta investigación se demuestra, entre otros aspectos, no sólo el arraigado hermanamiento que existe entre la Teoría y la Historia de la Educación, sino también el reto que como investigadores tenemos de, compartiendo las palabras de los autores: “... explorar [y reivindicar] nuevas fuentes de investigación que abran vías para la interpretación del pensamiento de determinados autores cuyas obras están ocupando un espacio destacado en la justificación y fundamentación de la práctica educativa actual” (Igelmo y Quiroga, 2014, 185).

En el siguiente texto, suscrito por Salam Adlbi, el lector disfrutará profundizando sobre la Pedagogía de la alteridad y las vivencias que ciertas alumnas españolas musulmanas han experimentado durante su formación académica. La diversidad en el aula aparece como tema emergente no tanto por su contenido, al que cada vez estamos más acostumbrados, sino por la necesidad de recibir un nuevo enfoque pedagógico que, más allá de la innovación, sea realmente efectivo. Sólo así conseguiremos alcanzar un escenario real de respeto y diálogo donde desaparezca la desconfianza que algunos de los profesores mostraron con respecto al potencial de estas estudiantes. Esa misma confianza que también aparece como un factor clave de las experiencias positivas pues: "Se puede concluir que para las entrevistadas, ha sido igual de importante la confianza depositada por sus profesores en ellas, como la falta de la misma” (Adlbi, 2014, 213). ¿Qué es la educación, debemos preguntarnos a la luz de estos resultados, sino confianza en estado puro?, ¿llegará un día en que aceptemos, como se sugiere en el texto, que la pedagogía no tiene cultura, ni raza, ni sexo?

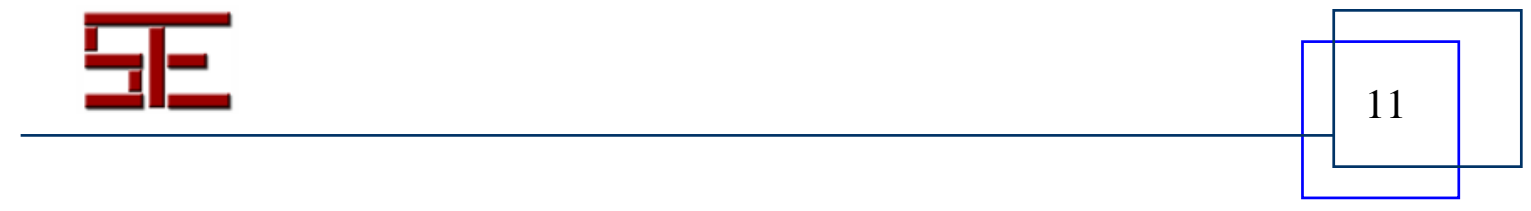




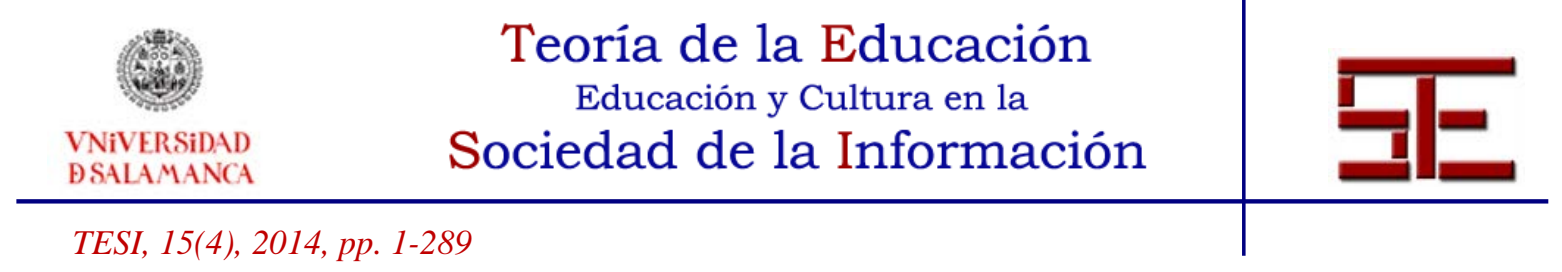

Precisamente en relación con esta última variable encontramos el escrito titulado "La perspectiva de género y el papel de la universidad en el siglo XXI", firmado por las profesoras Inmaculada López-Francés y Victoria Vázquez Verdera. Reflexionando sobre aspectos que inevitablemente tienen su repercusión en la docencia que las autoras desempeñan, encontramos un sempiterno juicio crítico que sopesa el papel y los intereses que las universidades presentan frente a una variable tan polémica como necesaria: el género. Aspecto de partida para una aspiración mucho mayor pues, según nos confiesan: "Nuestra línea de investigación y docencia emergentes parten del deseo de compartir la búsqueda hacia un cambio de paradigma a favor de la centralidad de la sostenibilidad de la vida” (López y Vázquez, 2014, 242). Plausible ideal que corrobora el gran caudal de la fontana del desear de nuestras compañeras y la fragancia de juventud que exudan las páginas de este monográfico.

Por último, aunque no por ello menos importante, volveremos a estrechar los campos de la Historia y la Teoría de la Educación de la mano de Mariano González Delgado y su estudio sobre las continuidades y los cambios acontecidos en las disciplinas escolares. Idas y venidas, encuentros y desencuentros que: “... no siempre obedecen a un patrón cultural creado en las instituciones escolares” (González Delgado, 2014, 263) pues, siguiendo con sus ideas, todo campo se halla en relación con otros ámbitos y formas de poder. La Historia del Currículum se presenta por tanto como un fértil campo de investigación al que nuestra disciplina puede y debe contribuir.

Estos son los autores. Sin duda no están todos los que son, pero creemos haber alcanzado una significativa muestra de las investigaciones que, lideradas por jóvenes académicos, emergen con soltura desde el campo de la Teoría de la Educación. Todos ellos han llegado a este punto a través de un camino enriquecedor, pero no por ello falto de espinas, como ya expuse en la primera parte de estos párrafos. Gracias a su esfuerzo, constancia y saber hacer, los autores han demostrado -y siguen haciéndolo sin descanso- ser merecedores del éxito académico que una publicación como la que nos ocupa certifica. Habiendo superado con ello el monomito del "viaje del héroe”, que bien nos podría servir de metáfora a la hora de concretar la vida del joven investigador. De esta manera, éste se ve envuelto en un periplo donde es atraído por los desafíos que le rodean, pero siendo incapaz de superarlos sin un proceso de separación, iniciación y redescubrimiento (Campbell, 1998). Etapas tan claramente identificables como el papel que el mentor -imprescindible rodrigón al que aferrarse sin aceptar exclusivamente su rol de "patrocinante" (Bourdieu, 2008)- representa para una juventud deseosa de ganarse su sitio, y no sólo encontrárselo o heredarlo.

Por sus frutos conocerás el árbol, suele bíblicamente afirmarse. Es por ello que también solicitamos a los autores que nos informaran de los tres hitos que mejor los identifican como miembros del área de Teoría de la Educación. Sin ánimo de establecer innecesarias comparaciones, y dejando de lado los premios que varios de ellos ya

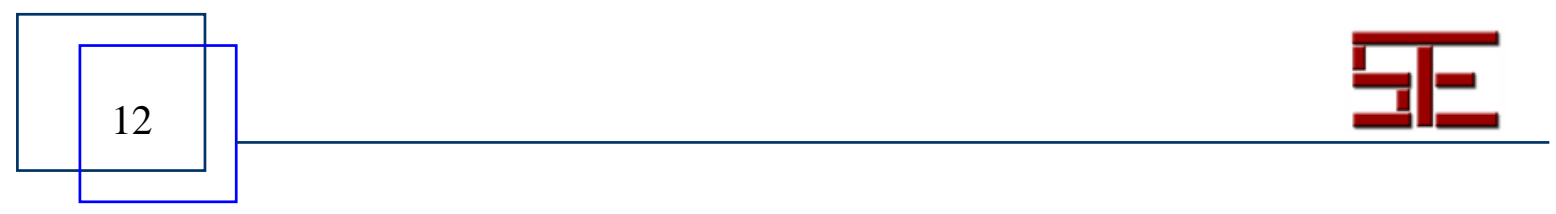




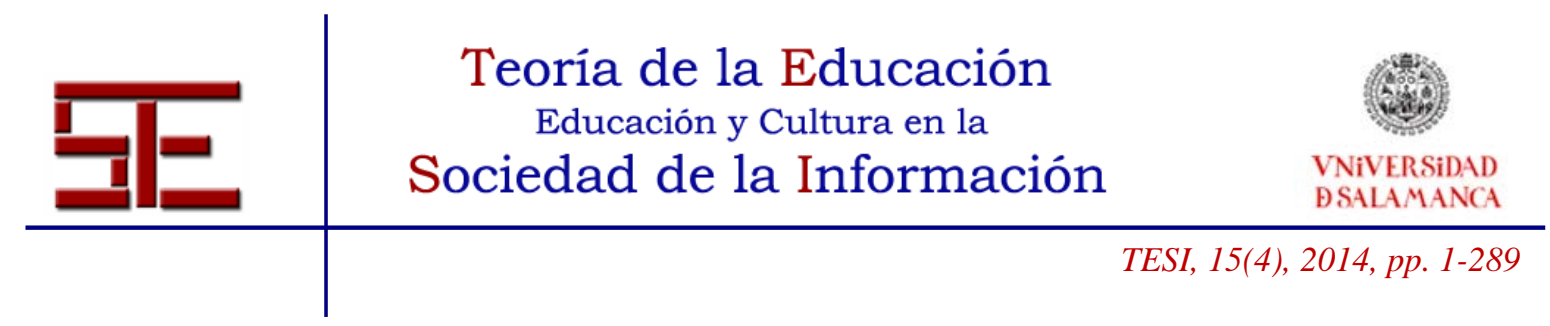

poseen, así como las estancias realizadas y los grupos de investigación a los que pertenecen, todos incluyeron entre sus tres prioridades artículos que dejaban constancia de la notoriedad que supone haber sido ya capaz de publicar en revistas del nivel de: Revista Española de Pedagogía, Bordón, Educación XX1, Pedagogía Social: Revista Interuniversitaria, Revista de Educación, Revista de Docencia Universitaria, Revista Iberoamericana de Educación, Teoría de la Educación: Revista Interuniversitaria o la propia Teoría de la Educación: Educación y Cultura en la Sociedad de la Información, por no señalar otras como Encounters on Education, Sociology Mind, International Journal for the Historiography of Education o Educational Theory. Tan sólo algunos ejemplos de cómo la juventud de este número, lejos de reducirse a la inexperiencia, también puede medirse en sexenios.

Adicionalmente, y aun siendo incompleto, sirva el anterior listado para entender por qué cualquiera de los autores aquí presentados podría haber coordinado este monográfico con igual o mayor destreza que como hemos tenido a bien llevar a cabo. Aprovecho por tanto estos momentos finales para dar las gracias a todos ellos por su diligencia durante estos meses de revisión y maquetación, especialmente a Jon Igelmo, también coeditor de este monográfico, pues sin su profesionalidad y su saber hacer hubiera sido imposible alcanzar la calidad obtenida. De igual forma, sería un error imperdonable cerrar estos párrafos sin agradecer al profesor Joaquín García Carrasco, así como a su equipo, la oportunidad de dar a conocer nuestro trabajo en la manera que nos ocupa. Él es el verdadero texto vivo que mejor constata la armónica relación que existe entre la experiencia de los años y la emergente juventud. Sin él, este número nunca hubiera visto la luz.

Por último, no quisiera finalizar sin apelar de nuevo a la condescendencia y el cuidado que la lectura de estos párrafos requiere. Como joven académico que soy, admito la insolencia que en algunos puntos he cristalizado al prestar la pluma al corazón y no sólo a la razón. Prometo que no ha sido porque mi voluntad haya flaqueado sino porque, precisamente, ha prevalecido. Pequeños pecados estilísticos que solamente pueden ser interpretados por la vehemencia de la juventud o la sabiduría de la experiencia, ¡cuándo, si no es al principio o al final de nuestras carreras, es lícito exclamar en un texto académico! Entre ambas etapas media la responsabilidad propia del profesional, seguro de sus acciones pero también temeroso de sus consecuencias, aunque tampoco es menos cierto que es precisamente esa responsabilidad la que puede hace sentir jóvenes a muchos viejos y viejos a muchos jóvenes.

Espero que mis palabras no sean indiferentes a nadie. Mentiría si lo negara. Pero también sospecho que es posible que no encuentren comprensión en quienes crean que me equivoco, quizá y entre otros motivos, por considerar que he realizado una desidiosa apología de la vagancia del joven que delega demasiado en las generaciones que le precedieron o que, irrelevantemente, me he centrado en ciertos aspectos que poco tienen

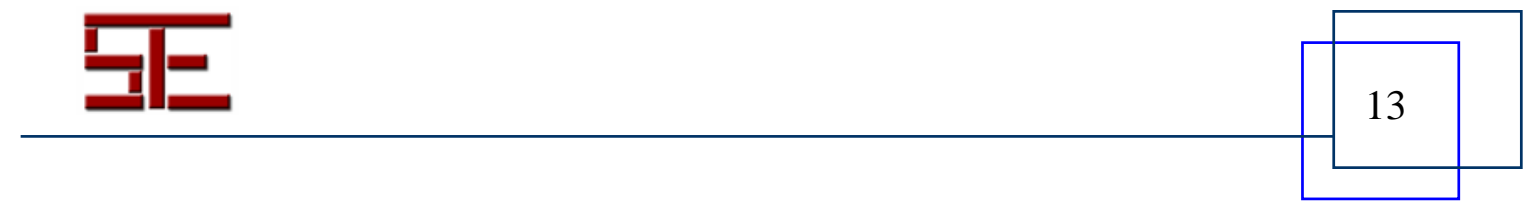




\section{\begin{tabular}{c} 
Teoría de la Educación \\
Educación y Cultura en la \\
$\begin{array}{c}\text { VNiVERSIDAD } \\
\text { DSALAMANCA }\end{array}$ \\
\hline TESI, 15(4), 2014, pp. 1-289
\end{tabular}}

que ver con la Teoría de la Educación en sentido estricto. A estos compañeros les animo a no desenterrar el hacha de guerra, pues no hay necesidad alguna. Mejor busquemos juntos la mesura que reside en las irónicas y sarcásticas -pero no por ello menos ciertasrecomendaciones que David Labaree ofrece a los jóvenes académicos de nuestro campo:

Emerging scholars in the field of education should keep these counter-principles of professional practice in mind: Be wrong; be lazy; be irrelevant; and think of your work as an effort to balance the values of truth, justice and beauty (Labaree, 2011, 74).

Si inicié esta presentación con las palabras de Ortega y Gasset, quien nos recordaba la importancia del desear sobre el deseo ya cumplido, y me aferré a sus ideas durante la exposición de mis argumentos, no será por tanto extraño que acuda también a él en estos momentos finales. Seré preciso: sin juventud no tardaremos en observar cómo se seca la fontana del desear. Es gracias a su virtud ponderada -entre el inconformismo y la obediencia- junto con el compromiso de los que en su día fueron jóvenes -entre la empatía y el paternalismo- que el progreso de nuestro campo y de la humanidad misma es posible. A todos aquellos que se sientan jóvenes, independientemente de las arrugas que surquen sus rostros o de las cicatrices que ribeteen sus corazones, les digo a modo de despedida:

Sed entusiastas, verted a manos llenas y en toda pureza vuestra vida. Pedid siempre sobre el ayer un mañana, sobre las viejas ideas exigid ideas nuevas. Mirad que sólo los jóvenes se encienden, y sólo así, a la hora del crepúsculo, podréis recogeros llevando vuestra alma impregnada de universo. (Ortega y Gasset, 2004, 168).

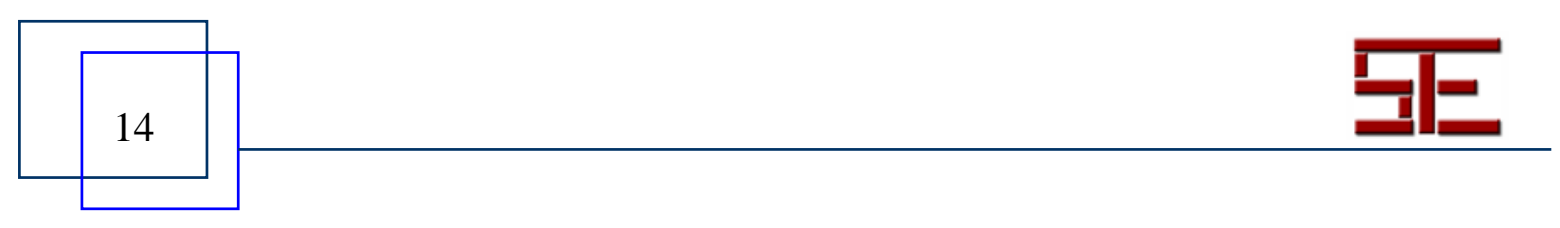




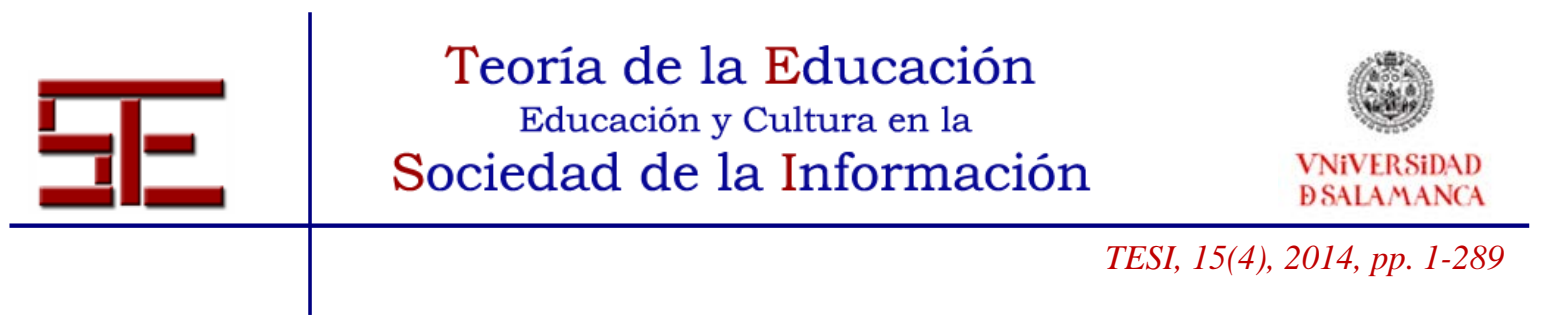

\section{REFERENCIAS}

ABC. (2012). Hwang Woo-suk, el veterinario que engañó al mundo con una clonación humana. Extraído de http://www.abc.es/20120224/archivo/abci-clonacion-hwang201202241142.html

Adlbi Sibai, S. (2014). Pedagogía de la Alteridad: Experiencias en el sistema educativo de las alumnas españolas musulmanas. Teoría de la Educación. Educación y Cultura en la Sociedad de la Información, 15(4), 211-240.

Aguilar Piñal, F. (1967). Los comienzos de la crisis universitaria en España. Antología de textos del siglo XVIII. Madrid: Magisterio Español.

Alonso Díaz, L. y Yuste Tosina, R. (2014). Teorías de la educación de adultos que subyacen en el uso de videojuegos. Teoría de la Educación. Educación y Cultura en la Sociedad de la Información, 15(4), 160-183.

Arbués, E. (2014). Presente y futuro de la educación para la ciudadanía en Europa. Teoría de la Educación. Educación y Cultura en la Sociedad de la Información, 15(4), 85106.

Bourdieu, P. (2008). Homo academicus. Argentina: Siglo XXI.

Carr, W. (2006). Education without theory. British Journal of Educational Studies, 54(2), 136-159. Doi: 10.1111/j.1467-8527.2006.00344.x.

Campbell, J. (1998). El héroe de las mil caras. Psicoanálisis de un mito. Méjico: Fondo de Cultura Económica. [Primera edición, 1949].

De Villena, L. A. (1975). La Revolución cultural. Desafío de una juventud. Barcelona: Planeta.

Esteve, J. M. (2010). Educar: un compromiso con la memoria. Barcelona: Octaedro.

Fernandes Gomes, N. y Hernández Serrano, M. J. (2014). Tecnologias e modelos de aprendizagem emergentes no ensino superior. Propostas e aplicações de inovações. Teoría de la Educación. Educación y Cultura en la Sociedad de la Información 15(4), 134-159.

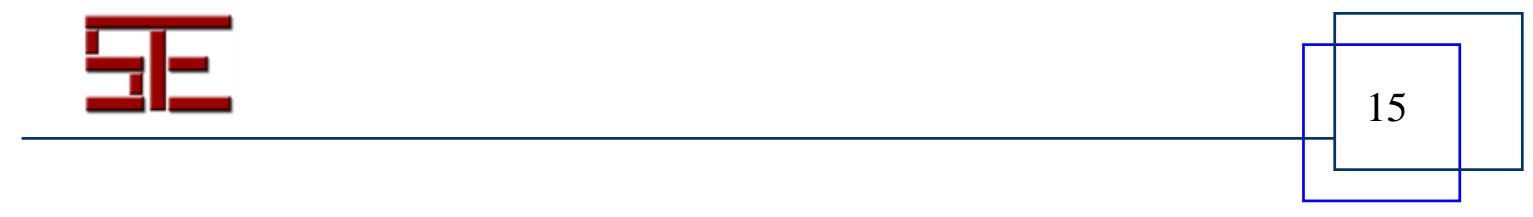




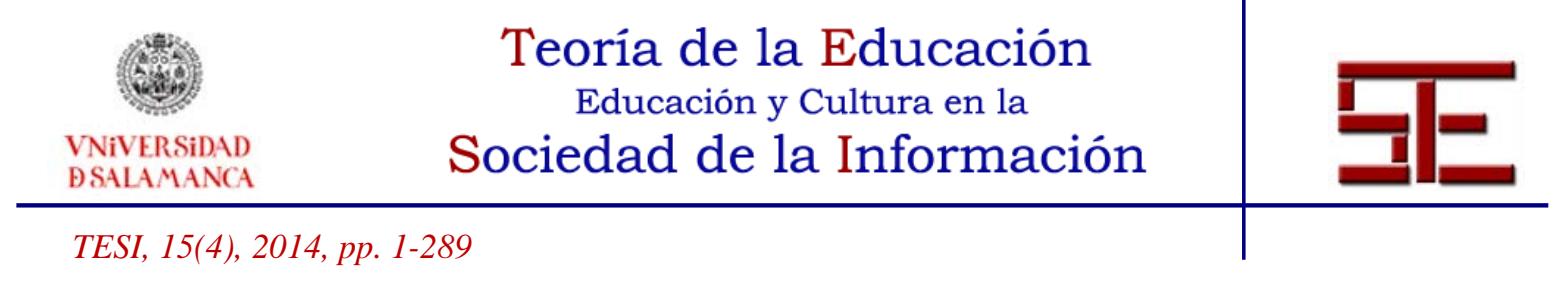

García Farrero, J. (2014). Presencia de la pedagogía en el acto de caminar: homo viātor, nomadismo y formación. Teoría de la Educación. Educación y Cultura en la Sociedad de la Información15(4), 56-84.

Giner de los Ríos, F. (1922). Obras completas, Vol. VII. Madrid: La Lectura.

González Delgado, M. (2014). Continuidades y cambios en las disciplinas escolares: Apuntes para una teoría sobre la Historia del Currículum. Teoría de la Educación. Educación y Cultura en la Sociedad de la Información15(4), 262-289.

González Geraldo, J. L. (2014a). Hacia una Universidad más Humana. ¿Es superior la educación superior? Madrid: Biblioteca Nueva.

González Geraldo, J. L. (2014b). Elucubraciones inquisitivas desde la torre de marfil. En R. M. Ytarte, M. Díaz y E. Portal (Coords.). La pedagogía social como formación, investigación y compromiso con la sociedad. Viejos y nuevos desafíos. Valencia: Nau Llibres.

Hesse, H. (1975). Demian. Historia de una juventud. Madrid: Alianza. [Primera edición, 1919].

Hesse, H. (2005a). Bajo las ruedas. Madrid: Alianza. [Primera edición, 1906].

Hesse, H. (2205b). El juego de los abalorios. Madrid: Alianza. [Primera edición, 1943].

Igelmo Zaldívar, J. y Quiroga Uceda, P. (2014). “Las palabras son también hechos”: Quentin Skinner, el giro contextual y la Teoría de la Educación. Teoría de la Educación. Educación y Cultura en la Sociedad de la Información15(4), 184-211.

Jofre, A. y Mari, S. M. (2014). Constructivist pedagogy at work in a realist classroom. A case study exploring college student's attitudes towards science. Teoría de la Educación. Educación y Cultura en la Sociedad de la Información, 15(4), 34-55.

Kuhn, T. S. (2001). La estructura de las revoluciones científicas. Méjico: Fondo de Cultura Económica. [Primera edición, 1962].

Labaree, D. F. (2011). A Sermon on Educational Research. International Journal for the Historiography of Education, 2, 74-83.

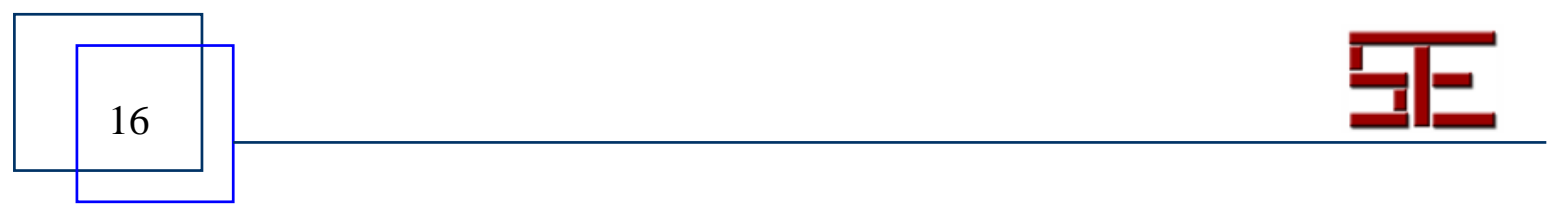




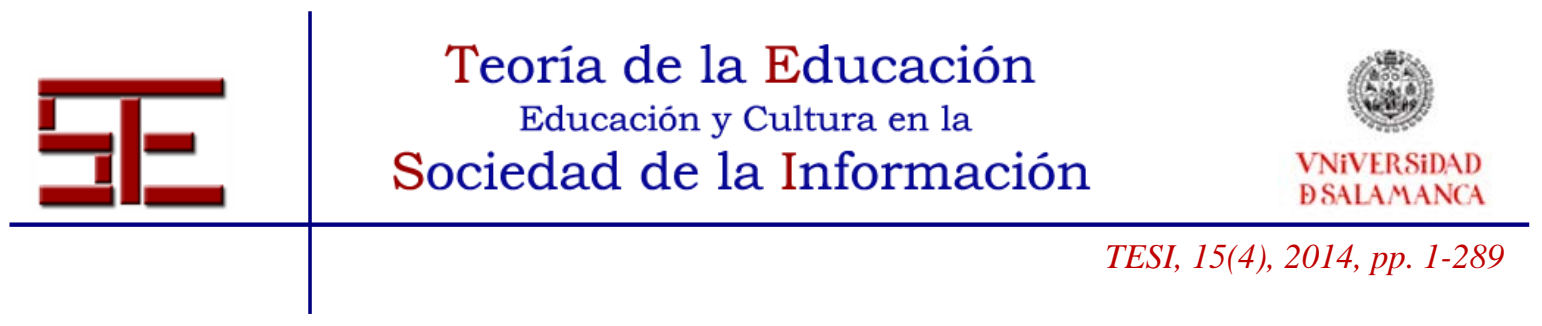

Labbé, C. (2010). Ike Antkare, one of the great stars in the scientific firmament", ISSI Newsletter, (6)2, pp.48-52. Disponible en http://hal.inria.fr/docs/00/71/35/64/PDF/TechReportV2.pdf

Laudo, X. (2014). La Pedagogía Líquida: ¿Imaginario Pedagógico o Teoría de la Educación? Teoría de la Educación. Educación y Cultura en la Sociedad de la Información, 15(4), 19-33.

Llopis, R. (1920). Posición que la juventud debe adoptar en el momento histórico actual. Cuenca: Emilio Pinós.

López, E. D., Robinson, N. y Torres, D. (2012). Manipulating Google Scholar Citations and Google Scholar Metrics: simple, easy and tempting. EC3 Working papers, 6.

López Francés, I. y Vázquez Verdera, V. (2014). La perspectiva de género y el papel de la universidad en el siglo XXI. Teoría de la Educación. Educación y Cultura en la Sociedad de la Información, 15(4), 241-261.

Martínez, J. L. (1976). El mundo antiguo IV. China/Japón. Méjico: Secretaría de Educación.

Nature. (2014). Publishers withdraw more than 120 gibberish papers. Extraído de http://www.nature.com/news/publishers-withdraw-more-than-120-gibberish-papers1.14763

Nóvoa, A. (2014). What is educational research for? European Conference on Educational Research. Oporto, 2-5 septiembre. [Discurso oral].

Orlandis, J. (1966). La crisis de la universidad en España. Madrid: RIALP.

Ortega y Gasset, J. (1930). La rebelión de las masas. Madrid: Revista de Occidente. [Páginas correspondientes a la edición de 1996. Santiago de Chile: Andrés Bello].

Ortega y Gasset, J. (1969). La Pedagogía Social como programa político. En Obras completas, vol. 1. Madrid: Revista de Occidente. [Conferencia pronunciada en 1910].

Ortega y Gasset, J. (2004). Misión de la Universidad. Y otros ensayos sobre Educación y Pedagogía. Madrid: Revista de Occidente en Alianza Editorial. [Primera edición del texto principal, 1930].

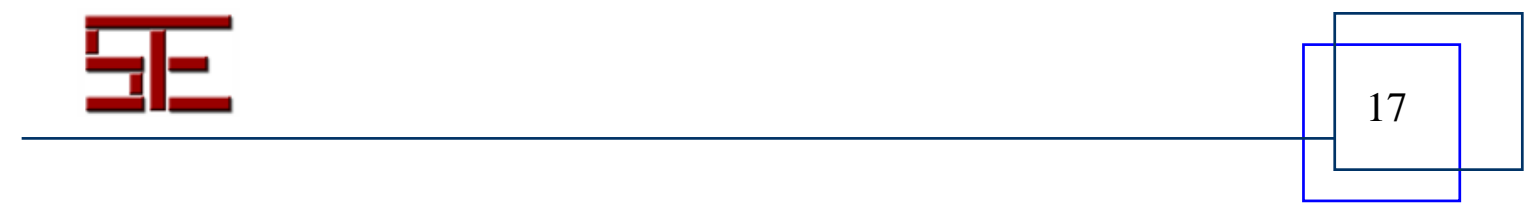




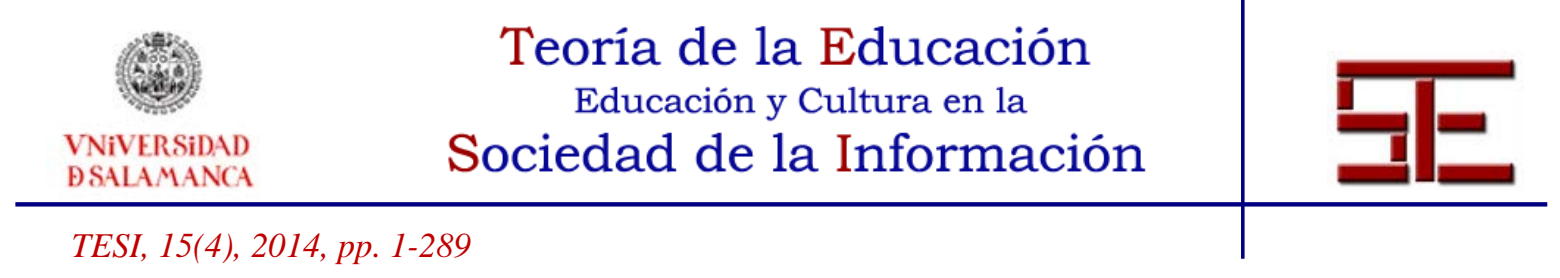

Penalva, J. (2011). Corrupción en la Universidad. El ocaso de la educación. El triunfo de la endogamia. Madrid: Ciudadela.

Ramió, C. (2014). Manual para los atribulados profesores universitarios. Guía de supervivencia. Madrid: Catarata.

Rousseau, J. J. (1997). Discurso sobre las ciencias y las artes. Buenos Aires: Losada. [Primera edición, 1750].

Ruiz Paz, M. (1999). Los límites de la educación. Madrid: Unisón.

Sánchez Antolín, P. y Paredes Labra, J. (2014). La concreción de las políticas educativas de integración de las TIC europeas y españolas en la Comunidad de Madrid. Teoría de la Educación. Educación y Cultura en la Sociedad de la Información, 15(4), 107-133.

The Guardian. (2014). How computer-generated fake papers are flooding academia. Extraído de http://www.theguardian.com/technology/shortcuts/2014/feb/26/howcomputer-generated-fake-papers-flooding-academia

The Independent. (2014). Research team apologises for errors in fake stem cell breakthrough. Extraído de http://www.independent.co.uk/news/science/research-teamapologises-for-errors-in-fake-stem-cell-breakthrough-9579973.html

The Slow Science Academy. (2010). The Slow Science Manifesto. Extraído de http://slow-science.org/

UNIVENDEBAT. (2012). Manifiesto por unas universidades a la altura de sus misiones. Extraído de http://www.univendebat.eu/manifeste/manifiesto-parauniversidades-a-la-altura-de-sus-misiones/ [Manifiesto susceptible de ser firmado online]

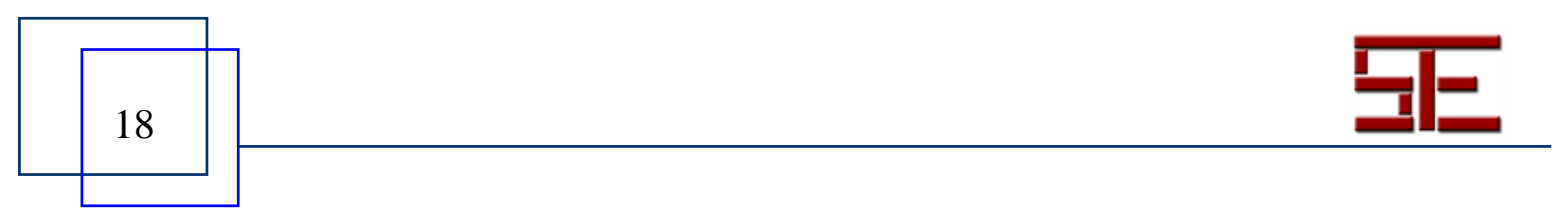

